\title{
Marginal Resection of Mandible for Treatment of Central Giant Cell Granuloma
}

\author{
Tatiane Fonseca Faro ${ }^{1 *}$, Gabriela Madeira Araújo', José Rodrigues Laureano Filho, \\ Ricardo José de Holanda Vasconcellos ${ }^{2}$ and Emanuel Dias de Oliveira e Silva ${ }^{2}$
}

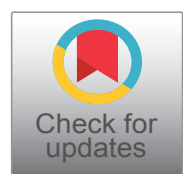

${ }^{1}$ Master's Student, Oral and Maxillofacial Surgeon, Department of Oral and Maxillofacial Surgery, School of Dentistry, University of Pernambuco, Brazil

${ }^{2}$ Professor, Oral and Maxillofacial Surgeon, Department of Oral and Maxillofacial Surgery, School of Dentistry, University of Pernambuco, Brazil

*Corresponding author: Tatiane Fonseca Faro, DDS, Master's Student, Oral and Maxillofacial Surgeon, Department of Oral and Maxillofacial Surgery, School of Dentistry, University of Pernambuco, 1650 General Newton Cavalcanti Avenue, Recife, PE, 54-753-220, Brazil, Tel: +005581996376494

\begin{abstract}
Central giant cell granuloma (CGCG) is an uncommon benign bone lesion that occurs in the mandible and maxilla and accounts for approximately $7 \%$ of all benign tumors of the jaws. The clinical behavior of CGCG is classified as aggressive or non-aggressive based on clinical and radiographic features. CGCG usually occur in patients less than 30 years of age. The radiological findings are diverse, ranging from small unilocular to large multilocular lesions. Treatment can be non-surgical (alpha interferon, calcitonin and corticosteroids) or surgical (curettage, enucleation and en bloc resection). This paper reports a case of a 27 -year-old male patient with a diagnosis of CGCG in left mandible that was treated with marginal resection.
\end{abstract}

\section{Keywords}

Giant cell granuloma, Mandible, Surgery, Diagnosis, Treatment

\section{Introduction}

Central giant cell lesion was initially denominated a "reparative giant cell lesion" based on the hypothesis that it was the result of a local repair process. However, as some lesions exhibit aggressive behavior similar to a neoplasm, the more correct nomenclature is central giant cell granuloma (CGCG) $[1,2]$.

CGCG occurs more frequently in women, is generally diagnosed prior to 30 year of age and affects the man- dible more than the maxilla [3]. The World Health Organization defines CGCG as an intraosseous lesion formed by fibrous cellular tissue containing multiple hemorrhagic foci in a cluster of multinucleated giant cells $[4,5]$.

The clinical behavior of CGCG ranges from slow asymptomatic growth to bone lysis and the resorption of dental roots [4]. This lesion is classified based on clinical and radiographic features as aggressive or non-aggressive, depending on the occurrence of pain, the speed of the growth, the perforation of the bone cortex and the tendency toward recurrence (Table 1) $[6,7]$.

Radiographically, CGCG exhibits a radiolucent unilocular or multilocular area with generally well-defined margin [8] and possible expansion of the cortical bone,

Table 1: Central giant cell granuloma classification criteria.

\begin{tabular}{|l|l|l|}
\hline & Group I \\
Aggressive & Group II & Non-aggressive \\
\hline Lesion size & $\geq 5 \mathrm{~cm}$ & $<5 \mathrm{~cm}$ \\
\hline Rapid growth & Yes & No \\
\hline Root resorption & Frequently & No \\
\hline Tooth displacement & Frequently & No \\
\hline Perforation of bone cortex & Frequently & No \\
\hline $\begin{array}{l}\text { Recurrence after } \\
\text { curettage }\end{array}$ & Yes & No \\
\hline
\end{tabular}

Classification proposed by Chuong, et al. and adapted by Peacock, et al. [6,7]. 


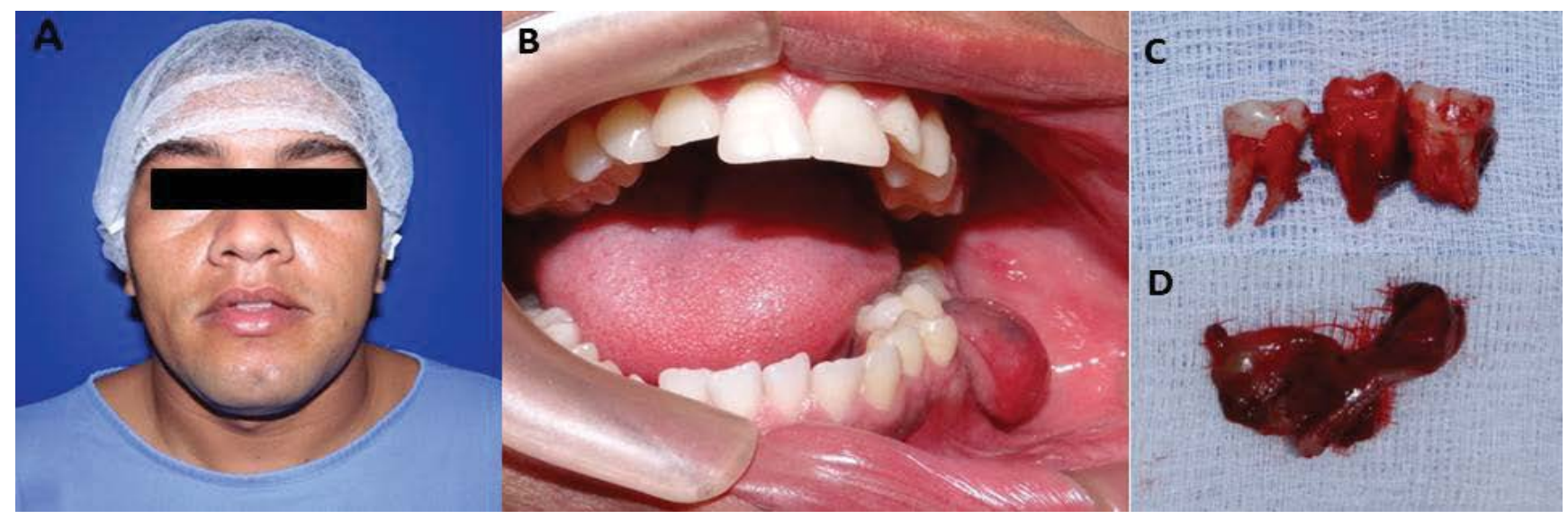

Figure 1: A) Front view of patient, revealing no facial asymmetry or camber; B) Increased volume in vestibular gingival tissue in region of left molars; C) Teeth removed during biopsy; D) Lesion tissue collected during biopsy.

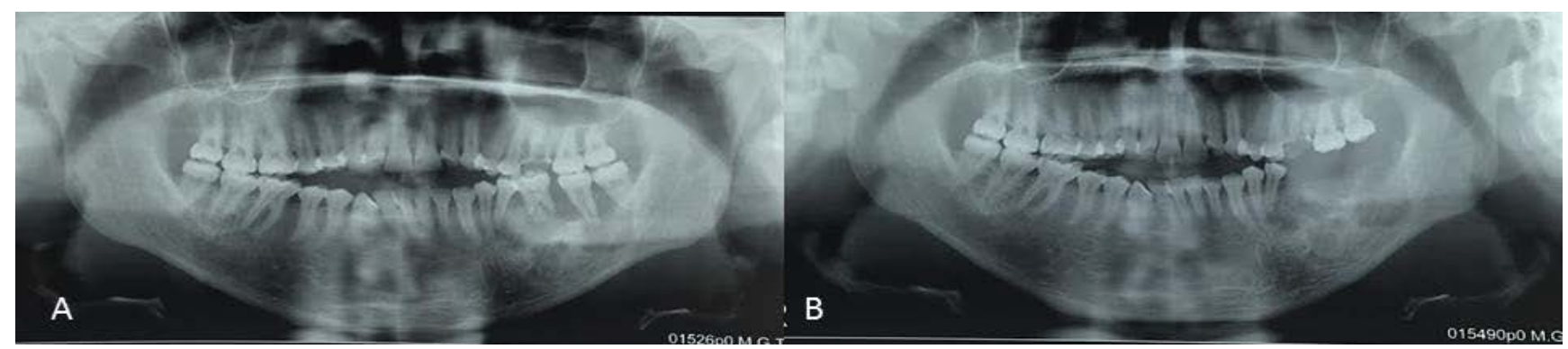

Figure 2: A) Panoramic radiograph of jaws revealing lesion and association with teeth in left mandibular region; B) Panoramic radiograph of jaws after biopsy of lesion.

cortical perforation, soft tissue involvement and, in aggressive cases, root resorption of adjacent teeth [2-5].

Lesions with multinucleated giant cells are part of the differential diagnosis of CGCG, such as aneurismal bone cyst, osteoid osteoma, brown tumor of hyperparathyroidism and cherubism $[8,9]$. The differential diagnosis with brown tumor of hyperparathyreoidism, however, requires a laboratorial investigation for the determination of calcium, phosphate, parathyroid hormone and alkaline phosphatase levels $[5,9]$.

\section{Case Report}

A 27-year-old male patient visited the Oral-Maxillofacial Surgery and Traumatology service of the Oswaldo Cruz University Hospital with a complaint of an increased volume in the vestibular gingival tissue in the posterior portion of the left mandible (Figure $1 \mathrm{~A}$ ) with a twomonth history. The physical examination revealed no facial asymmetry or cervical adenomegaly (Figure 2). The intraoral examination revealed an increased volume in the vestibular gingival tissue with a purplish color (Figure $1 B)$, bleeding upon examination, mobility of the left mandibular first molar and no associated pain symptoms.

The radiographic exam revealed a mixed lesion with an irregular contour extending from the region of the left mandibular second premolar to the left mandibular third molar, with displacement of the left mandibular first molar and bone resorption in the region of the left mandibular second and third molars (Figure 2A).
Incisional biopsy and extraction of the left mandibular first, second and third molars (Figure $1 \mathrm{C}$ and Figure 1D) and (Figure 2B) were performed to facilitate the removal of the lesion. The histopathological findings were suggestive of CGCG. Due to the histological similarity between CGCG and brown tumor of hyperparathyreoidism, laboratorial exams were performed for the determination of calcium $(9.3 \mathrm{mg} / \mathrm{dl})$, phosphorus $(3.9 \mathrm{mg} /$ $\mathrm{dl})$, alkaline phosphatase $(124 \mathrm{U} / \mathrm{L})$, calcitonin (less than $2 \mathrm{pg} / \mathrm{ml})$ and parathyroid hormone $(35 \mathrm{pg} / \mathrm{ml})$, the levels of which were normal.

After the diagnostic confirmation, surgery was performed under general anesthesia for the marginal resection of the mandible with a margin of safety to avoid recurrence (Figure 3B). For such, an incision was made in the region of the posterior mandibular alveolar ridge and mucoperiosteal detachment to demarcate the area of resection to be performed with chisels and a mallet. A submandibular incision was also performed, and osteotomy was achieved with the use of a reciprocating saw (Figure 3A). The left mandibular first and second premolars were included in the area of the resection (Figure $3 B$, Figure 4A, Figure 4B and Figure 4C).

The sample was sent for anatomopathological analysis, which confirmed the diagnosis of CGCG (Figure $3 C$ ). The sutures were removed after one week and the patient evolved with slight swelling, but no important complaints. At the six-month follow-up evaluation, the patient exhibited a normal facial contour (Figure 5A), 


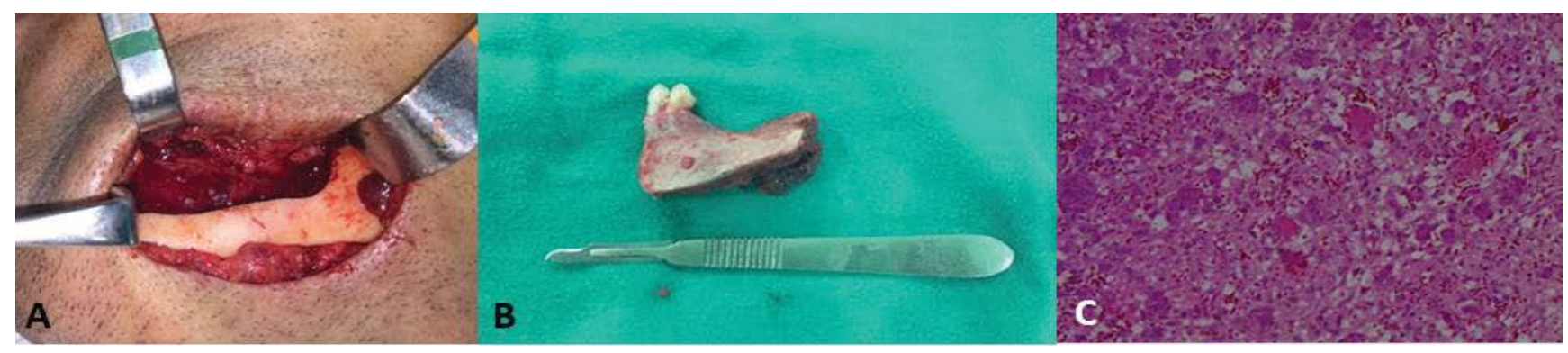

Figure 3: A) Submandibular surgical access with marginal osteotomy; B) Surgical piece of sectioned area; C) Histological cut revealing fragments of hypercellularized young connective tissue with intense monocellular inflammatory infiltrate, hemorrhagic exudate and multinucleated giant cells, confirming diagnosis of central giant cell granuloma.

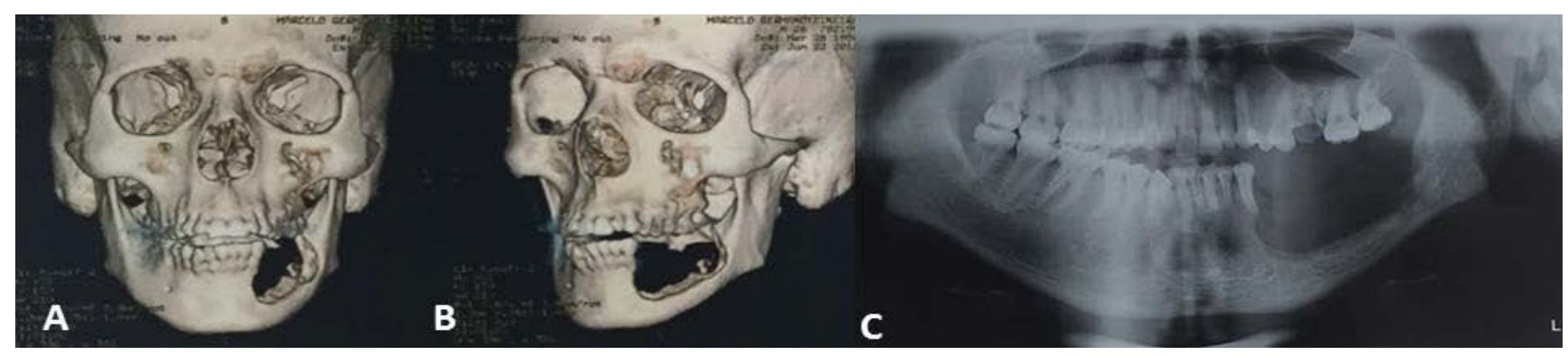

Figure 4: $A, B)$ Computed tomography reconstruction revealing area of resection; C) Panoramic radiograph after marginal resection.
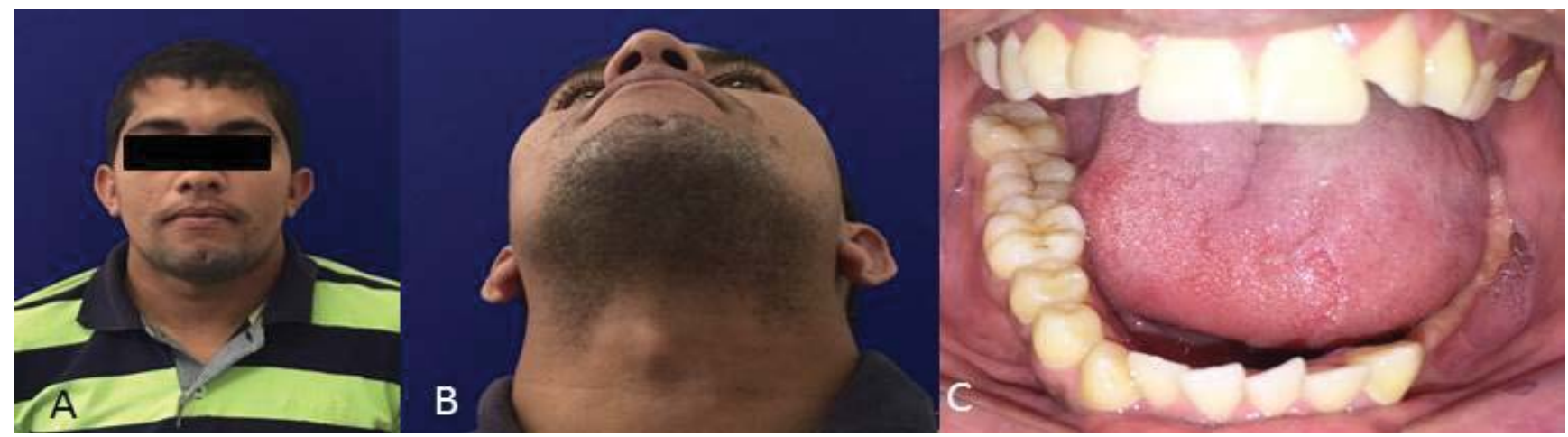

Figure 5: A) Front view of patient six months after surgery; B) Patient in cervical hyperextension, revealing slightly perceptible submandibular scar on left side; C) Intraoral aspect of sectioned area.

small visible scar in the submandibular region on the left side (Figure 5B), an intraoral defect and the absence of the teeth involved in the resection (Figure $5 \mathrm{C}$ ).

\section{Discussion}

According to the literature, CGCG is more frequent in the mandible and the female sex $[1,3-5,8,10]$ and is generally diagnosed in patients less than 30 years of age $[1,4]$. In the present case, the patient was a 27 -year-old male with CGCG in the posterior region of the mandible, which is in agreement with literature regarding location and age at the time of diagnosis.

The differential diagnosis was performed with other lesions that have multinucleated giant cells. Moreover, a laboratorial investigation was performed to differentiate CGCG from brown tumor of hyperparathyreoidism based on calcium, phosphorus, alkaline phosphatase, calcitonin and parathyroid hormone levels, since these lesions are clinically, radiographically and histopathologically identical [8].

The radiographic characteristics of giant cell lesions can vary from small periapical lesions to large destructive multilocular lesions involving the maxilla or mandible $[1,4]$. In the present case, the patient exhibited a multilocular granuloma with tooth displacement, the resorption of vestibular cortical bone and soft tissue infiltration. Based on the clinical and radiographic criteria of the classification adapted by Peacock, et al. (Table 1 ), the lesion was the aggressive type, as it was greater than $5 \mathrm{~cm}$ and exhibited vestibular cortical perforation, root displacement and rapid growth.

Recurrence rates range from 3 to $72 \%[1,4]$ in young patients, however, lesions with cortical perforation have a greater tendency toward recurrence $[4-6,10]$. Besides the biological behavior of the tumor, the treatment modality is also related to the recurrence rate $[1,5]$. The 
administration of alpha interferon, calcitonin and corticoids constitutes non-surgical treatment $[2,10]$, whereas curettage, curettage + peripheral ostectomy and en bloc resection are forms of surgical treatment $[2,4,5]$.

In a study involving nine patients with CGCG, Farrier, et al. chose surgical resection as definitive treatment with the maximum preservation of the bone to avoid substantial esthetic and functional impairment. The authors used subcutaneous calcitonin only on maxillary lesions with the aim of diminishing the area of resection. In the present case, the patient was submitted to surgical resection with the preservation of the basal bone of the mandible in an attempt to minimize functional and esthetic impairment.

En bloc marginal resection was performed following the histopathological confirmation, since it was a case of a large granuloma with cortical perforation. The surgical technique with the preservation of the basal bone enabled maintaining the facial contour. According to the literature, lesions surgically treated with resection or curettage and additional treatments have practically no chance of recurrence $[1,10]$.

The patient in the present case has been undergoing clinical and radiographic follow up for six months, with no signs of recurrence. In the study by Tosco, et al. [4], the eight cases of mandibular CGCG were treated with surgical resection with a $5 \mathrm{~mm}$ margin of safety, with clinical and radiographic follow up ranging from two to ten years. The authors performed mandibular reconstruction with a bone graft. In the present case, the patient continues to be in clinical and radiographic follow up and the subsequent reconstruction of the surgical defect is planned.

\section{Final Considerations}

The diagnosis of central giant cell granuloma is a challenge due to the clinical, radiographic and histopathological similarities with other multinucleated giant cell lesions of the jaws. Surgical therapy is widely accepted in such cases due to the lower rate of recurrence. However, there are alternative therapies with the aim of minimizing the irreversible esthetic impairment.

\section{References}

1. De Lange J, van Rijn RR, van den Berg $H$, van den Akker HP (2009) Regression of central giant cell granuloma by a combination of imatinib and interferon: A case report. $\mathrm{Br} J$ Oral Maxillofac Surg 47: 59-61.

2. Orzechowski PR, Takashima M, Romeiro RL, Santana JB, Campos MS (2012) Granuloma central de células gigantes: Relato de caso clínico. Rev Cir Traumatol Buco-Maxilo-Fac Camaragibe 12: 61-68.

3. Stavropoulos F, Katz J (2002) Central giant cell granulomas: A systematic review of the radiographic characteristics with the addition of 20 new cases. Dentomaxillofac Radiol 31: 213-217.

4. Tosco P, Tanteri G, laquinta C, Fasolis M, Roccia F, et al. (2009) Surgical treatment and reconstruction for central giant cell granuloma of the jaws: A review of 18 cases. J Craniomaxillofac Surg 37: 380-387.

5. Farrier SL, Farrier JN, Smart MK, Nash ES (2006) A 10year review of the occurrence and treatment of central giant cell granulomas, in a district general hospital. J Oral Pathol Med 35: 332-337.

6. Chuong R, Kaban LB, Kozakewich H, Perez- Atayde A (1986) Central giant cell lesions of the jaws: A clinicopathologic study. J Oral Maxillofac Surg 44: 708-713.

7. Peacock SZ, Jordan RCK, Schmidt BL (2012) Giant cell lesions of the jaws: Does the level of vascularity and angiogenesis correlate with behavior? J Oral Maxillofac Surg 70: 1860-1866.

8. Noleto JW, Marchiori E, Sampaio RK, Irion KL, Collares FB (2007) Aspectos radiológicos e epidemiológicos do granuloma central de células gigantes. Radiol Bras 40: 167-171.

9. Guerrissi JO (2013) Giant cells mandibular lesion: Surgical treatment with preservation of the Dentition. J Craniofac Surg 24: 1394-1396.

10. Lange J, Van den Akker HP (2005) Clinical and radiological features of central giant-cell lesions of the jaw. Oral Surg Oral Med Oral Pathol Oral Radiol Endod 99: 464-470. 